\title{
POSTERIOR WALL UTERINE RUPTURE - A CASE REPORT
}

\author{
Sravani Chithra1 ${ }^{1}$, Shery Angel Rajakumar², Gopalakrishnan ${ }^{3}$, Thirumal R ${ }^{4}$, Saranya Chitra ${ }^{5}$
}

\section{HOW TO CITE THIS ARTICLE:}

Sravani Chithra, Shery Angel Rajakumar, Gopalakrishnan, Thirumal R, Saranya Chitra. "Posterior wall uterine rupture - a case report". Journal of Evolution of Medical and Dental Sciences 2013; Vol2, Issue 38, September 23; Page: 7343-7346.

ABSTRACT: Uterine rupture is a potentially catastrophic event during childbirth by which the integrity of the myometrial wall is breached [1]. It can occur in an unscarred uterus or a uterus with a surgical scar. The incidence of uterine rupture in patients with history of a single caesarean section ranges from $0.2 \%$ to $1.5 \%$ which increases to $3.9 \%$ with two or more previous caesareans [2]. Here is a case of a 38 year old Mrs. X G2A1 at 28 weeks of gestation with history of dilatation and curettage in the past. Now admitted for correction of anaemia and later diagnosed to have posterior wall uterine rupture. The incidence of uterine rupture has been increasing due to increasing rate of caesarean sections. WHO data indicated that $75 \%$ of uterine ruptures still occurred in unscarred uteri with maternal mortality rate of $1-13 \%$ and perinatal mortality rate between $74 \%$ and $92 \%{ }^{[4]}$. KEYWORDS: Anaemia, Prostaglandin, Oxytocin, Haemoperitoneum, Posterior wall uterine rupture

INTRODUCTION: Uterine rupture is one of the most dreaded complications of childbirth where the integrity of myometrial wall is breached with potentially grave consequences to mother and fetus. It can be complete uterine rupture involving full thickness of uterine wall or incomplete uterine rupture where there is disruption of muscle but the overlying peritoneum remains intact [3]. The commonest sites of rupture are the previous scar in the uterus, lower uterine segment in the anterior wall of uterus [5].

Causes of uterine rupture are uterine scars due to caesarean section, hysterotomy, myomectomy, metroplasty and previous uterine perforation, cervical scars, oxytocic drugs, neglected obstructed labour, obstetric manipulation, trauma and rarely spontaneous rupture before onset of labour [4].

Patient presents with sudden feeling of giving way, alteration in shape of abdomen, bladder symptoms, tachycardia, hypotension, syncope, cessation of uterine contractions, scar tenderness. Foetal heart rate abnormalities such as tachycardia, variable, late, and prolonged decelerations are the most reliable warning signs [6].

CASE REPORT: Mrs. X, 38 years old, G2A1 at 28 weeks gestation with history of dilatation and curettage in the past was referred to the hospital as a case of anemia. Her haemoglobin was $5 \mathrm{~g} \%$.

Examination: Her general condition was fair, she was afebrile, weight - $72 \mathrm{Kgs}$, height $-156.5 \mathrm{cms}$, pallor was present, no icterus, and no pedal edema. Blood pressure - 100/70 mmHg. Pulse rate: $118 /$ min. Urine albumin absent. Chest, cardiovascular system, CNS examination was within normal limits. On per abdomen examination she had a 28 week size pregnancy with transverse presentation, liquor was clinically adequate, foetal heart rate (FHR) was 146/min regular, uterus was relaxed.

Investigation: Thyroid function test were within normal limits. 3 units of blood was transfused and her repeat haemoglobin was $5.8 \mathrm{~g} \%$. 


\section{CASE REPORT}

Fetal Doppler demonstrated absence of Diastolic flow in the umbilical artery. Within a few hours fetal heart rate was absent.



Intrauterine demise had occurred. She was induced labour with Prostaglandin gel 0.5mg (3 doses) and started on oxytocin infusion escalating dose. Cervix did not respond to the induction techniques.

Hence scan was done to rule out uterine rupture, Scan showed foetus in abdominal cavity with free fluid in the pouch of douglas.



Laparotomy was done and the dead foetus was taken out from the abdominal cavity. 3 litres of hemoperitoneum was noticed with a posterior wall uterine rupture. Repair of the posterior wall rupture was done. Bilateral fallopian tubes and ovaries appeared normal. 


\section{CASE REPORT}

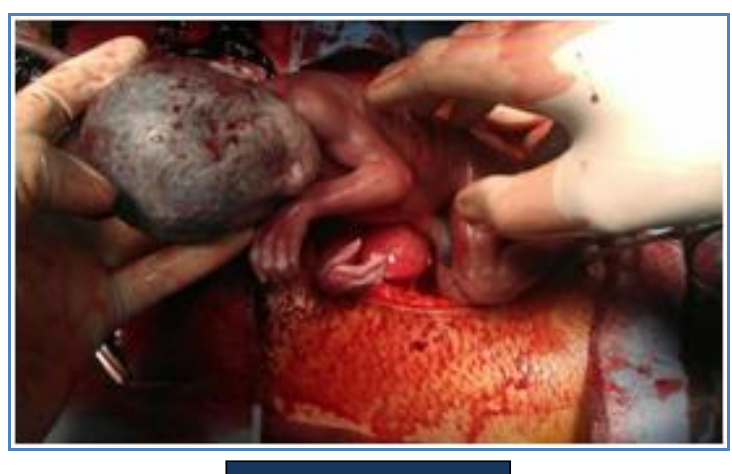

DEAD FOETUS

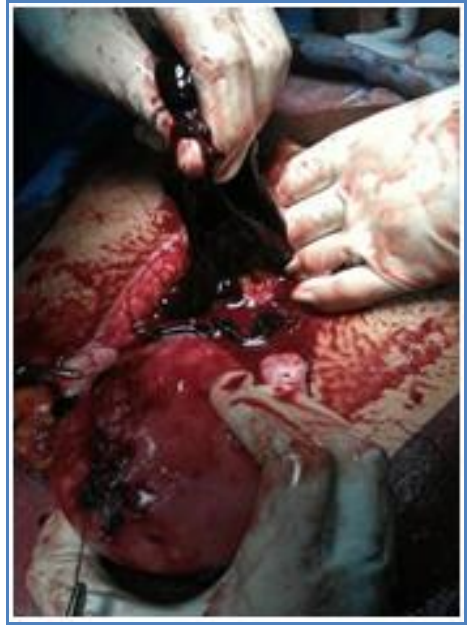

HAEMOPERITONEUM

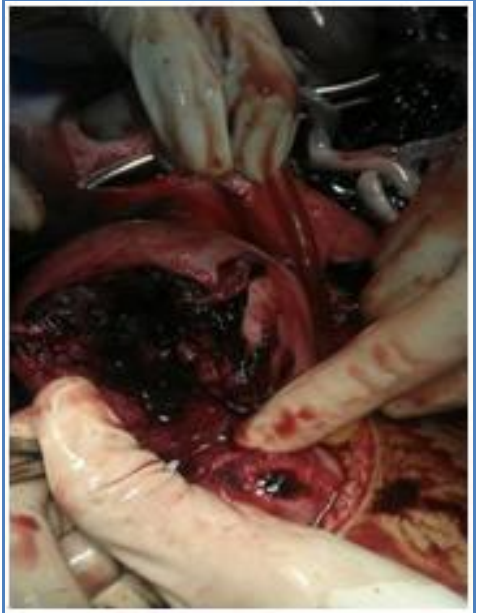

POSTERIOR UTERINE WALL RUPTURE

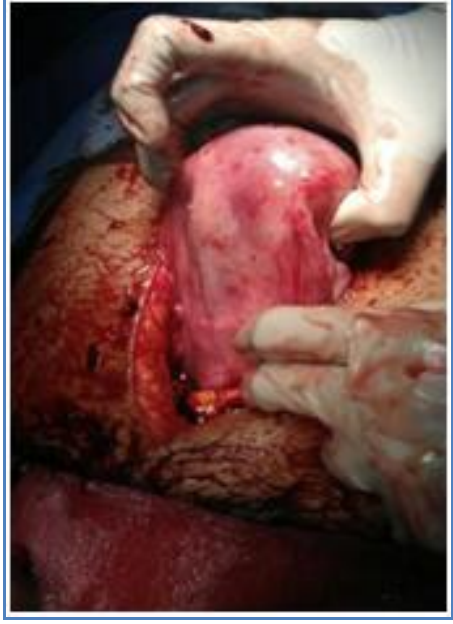

ANTERIOR UTERINE WALL



POSTERIOR UTERINE WALL RUPTURE SUTURED

DISCUSSION: Uterine rupture usually occurs in the presence of previous surgical scar in the uterus. Anterior wall uterine rupture is more common compared to posterior uterine wall [3]. In this case the surprisingly, she had only a history of dilatation and curettage in the past, Patient was hemodynamically stable except for tachycardia and had posterior wall uterine rupture. 
Forceful curettage in the previous pregnancy could have caused the posterior wall to thin out and vulnerable to rupture. Since she was hemodynamically stable uterine rupture could not be diagnosed clinically at an early stage and was ruled out using ultrasonogram. The posterior wall rupture was not iatrogenic. Her haemoglobin level was low in spite of blood transfusion and she had persistent tachycardia hence the rupture should have occurred long before she came to the hospital. The rupture was sutured but she has an increased risk of uterine rupture in consequent pregnancies. She was advised to delay conception in order to allow the scar to heal well and regular antenatal checkups for the next pregnancy. Once uterine rupture occurs only 10-37 min should be taken between diagnosis and delivery, otherwise foetal morbidity is inevitable [6].

\section{REFERENCES:}

1. Wang PH, Yuan CC, Yang MJ, Choa HT, Ng HT: Posterior uterine wall rupture during labour. Hum reprod 2000 May; 15(5):1198-9.

2. K. Navaratnam, P. Ulaganathan, MA. Akhtar, SD. Sharma, MG. Davies: Posterior uterine rupture causing fetal expulsion into the abdominal cavity: a rare case of neonatal survival. Case reports in obstetrics and gynaecology 2011, article ID 426127.

3. Bank MI, Thisted DL, Krebs L: Spontaneous rupture in the posterior wall of an unscarred uterus. J Obstet Gynaecol. 2011 may; 31(4):347-8.

4. Subrata Majumdar, Richard Warren, OlufelaIfaturoti: Posterior uterine wall rupture during labour with intact previous caesarean section scar. Nov 2007, volume 276(537-540)

5. DA miller, TM Goodwin, RB Gherman, RH Paul: intrapartum rupture of unscarred uterus. May 1997elsevier (671-673) obstetrics and gynaecology.

6. Walsh CA, O'Sullivan, Foley ME: Unexplained pre-labour uterine rupture in a term primigravida. 2006 obstetrics and gynaecology 108(3pt2) 725-727

\section{AUTHORS:}

1. Sravani Chithra

2. Shery Angel Rajakumar

3. Gopalakrishnan

4. Thirumal R.

5. Saranya Chitra

\section{PARTICULARS OF CONTRIBUTORS:}

1. $2^{\text {nd }}$ Year Post Graduate, Department of Obstetrics \& Gynaecology, Annamalai University.

2. Assistant Professor, Department of Obstetrics \& Gynaecology, Chettinad Hospital and Research Institute.

3. $2^{\text {nd }}$ Year Post Graduate, Department of Radiology, Annamalai University.
4. Senior Resident, Department of Orthopaedics, Chettinad Hospital and Research Institute.

5. Final Year Graduate, Department of Obstetrics \& Gynaecology, Chettinad Hospital and Research Institute.

\section{NAME ADDRESS EMAIL ID OF THE CORRESPONDING AUTHOR:}

Dr. Sravani Chithra, No. 3, Krishna Bhai Street, Gokulam Colony, T Nagar, Chennai - 600017.

Email-drsravanichithra@yahoo.com

Date of Submission: 03/09/2013.

Date of Peer Review: 04/09/2013.

Date of Acceptance: 18/09/2013.

Date of Publishing: 21/09/2013 